\title{
THE PARADIGM OF THE CREATIVE CLASS IN REGIONAL AND URBAN DEVELOPMENT REVISITED. AN OVERVIEW
}

JULIANNA FALUDI ${ }^{1}$

\begin{abstract}
Since the era of industrial capitalism when location started playing an important role in attracting industry and trade and boosting the economy, the role of knowledge and a high level of skills has grown in post-industrial regional economic theory. What makes the heated debate around creativity and the contribution of Richard Florida's work particularly valuable is that it fosters an interdisciplinary discussion about the role of creativity, culture, talent, and diversity in urban and regional development. Despite the vividness and edginess of these debates at times, it seems that the related criticisms, based on a body of evidence, did not originally penetrate policymaker discourse, and only one-and-ahalf decades later were embraced when problems stemming from socioeconomic crises and the flaws of creative policymaking reared their head more explicitly. Florida's revelations, which were elevated into the popular arena of city-level policies and governance, did not contain much that was new. This paper tracks how the concept of the "creative class" has been tested, argued about, rejected and applied since then on a wide set of practices and experiences in the urban and regional framework.
\end{abstract}

KEYWORDS: creative class, urban development, regional development, human capital

JEL: R58, R11

1 Julianna Faludi PhD is an associate professor at CUB, e-mail: faludisociology@gmail.com 


\section{INTRODUCTION}

The concept of creativity as a source of inspiration for a political agenda that is able to create a new labor and industry structure in urban contexts has gone through upheaval in the past two decades, but the tension between ideas about where development should come from - people or infrastructure -, existed earlier. Back in the early 1960s the challenge of how to create a vital urban life along with gradual and civic-driven renewal was on the agenda of Jane Jacobs (1961), who extensively criticized the urban planning policies of the post-war US. She pointed out the contrasting dynamics that were creating segregation and impoverishment, but also the renewal of some city areas, and stood up against the investment-driven, top-down approach to highway construction and large-scale development of the times that was destroying neighborhoods. Jacobs linked creative vibes and economic prosperity, and saw diversity and pedestrian activity as a source of renewal. Decades later, Florida clearly aligned himself with the symbolic role of "sidewalk-ballet" and diversity in cities (Jacobs 1961), and in his first book (2002) stepped into the role of a flaneur, captured by the diversity of the streets of New York City that inspired him to study the connection between the creative spirit and economic performance in different cities across the US.

Richard Florida's framework $(2002,2004,2005)$ subscribes to the pull theories of regional development, stressing the role of creativity in urban regeneration. Ever since his ideas spread, scholars have delivered a series of criticisms from different angles related to his theses, warning of their literal conversion into policies for all city contexts. Despite explicit concerns about methodology, a neglect of contextuality and history, and issues with the socioeconomic determinants of class formation based on educational governmental policies, Florida's catchy lists and suggestions have inspired an urban policy that in many cases has embraced the idea of attracting a creative class and forging investment to boost urban regeneration and new entrepreneurship and growth by implementing sets of measures in line with the concept of creativity.

The potential of culture for urban growth as an agenda for local and national policymakers was pushed forward in the popular domain by Landry and Bianchini (1995), who suggested channeling public investment into culture, while it was Landry's (2000) The Creative City. A Toolkit for Innovators that led to prescriptive urban policy based on the creative economy, shortly before the ideas of Florida and his book spread across the world. Landry provided rich illustrations of case studies, and promised all-context adaptable methods for urban politicians for addressing the problems of decay and creating hubs of creativity, whereby a business-oriented entrepreneurial approach to city 
management lay at the core of the manual. The view of creatives as free moving and gravitating toward favorable livelihoods - the direction of cause and effect repeatedly argued by Florida - can already be traced in this work. The former also stressed the benefits of centers as quality, diversity, and the just-in-time availability of experiences; predominantly large-city phenomena that are sought by creatives (Landry 2000, p.18: referenced by Sorensen et al. 2010). The Creative City agenda was found in the halls of municipalities well before the arrival of the Rise of the Creative Class (2002). Regarding the case of Amsterdam policymaking, Modder and Saris described it in the following way:

"Local observers confirm that the Dutch creativity debate was palpably 'speeded up by Richard Florida's attendance at the [Westergasfabriek] conference,' in the wake of which 'his happy message about the significance of the creative class for the regional economy has been reverberating through governmental and administrative halls in the Netherlands" (Modder and Saris 2005: 1 cited by: Peck 2012: 464)

Florida's book (2002) swiftly became popular, entering the columns of the most commonly read reviews. Diversity involving gays, artists, and hairdressers, and also more concretely defined non-manual jobs like teaching, engineering etc. that are associated with the notion of the phenomenon of expansive creativity were claimed to be appealing due to their flexible, self-employment- and entrepreneurial revitalization arrangements. A first wave of criticism came from homophobic and anti-immigrant groups that framed the approach as an attack on "business-oriented development strategies and suburban lifestyles," if not a frontal assault on "family values" (Peck 2005: 741). Further waves of critique came from the creatives themselves, and also from swathes of unemployed graduates who warned about their real-life conditions and perspectives that involved insecurity, a lack of welfare provision, and the need to take on two or three jobs that seemed to push them further away from the winning side. Moreover, communities and structures that could have provided spaces such as craft workshops, libraries, and theaters to bring together creative minds and disadvantaged populations in an egalitarian model of co-operation were overlooked in favour of an "air-brushed vision of café-society" (McRobbie 2016: 50). Voices were also raised about the lack of questioning of poverty and the housing of marginalized groups in cities in the creative agenda. Taken over by policies of governors and city mayors, the "rise of the creative class" paved the way for urban regeneration in dilapidated, culturally thriving areas that showed diversity, but it has also created a space for investment that has brought about gentrification, segregation, growing inequalities, and which has crowded out 
vulnerable groups, along with the core creatives themselves that were initially used as a magnet for capital investment. Lists of cities based on their creativity index have triggered policies adapted to the idea of boosting tourism in rural and remote areas, as well as attracting "talent" which could put cities on the list of competing global megalopolis.

Since the implementation of the policies, the visible consequences and body of experience related to creative city agendas have been documented in newer strands of research and expressed in movements. In the most recent reflection on the more-than-a-decade of creative class policies and the development paths of (mega)polices that have increased inequality, gentrification, and skyrocketing house rental costs, Florida (2017) suggests that solutions to problems should be delivered from the bottom-up, thus putting related decisions into the hands of elected mayors. In the already known vein of mapping the creative and service class in a city, the "New Urban Crisis" represents a newer toolkit that now seemingly puts inclusion on the urban creative agenda. Examples predominantly stem from the US experience but also from London, albeit lack a focus on contextual and historical differences.

The following material is divided into five sections, the first of which provides an overview of the Creative Class framework, while the next three evolve around the main arguments and counter-arguments that are underpinned by empirical scholarship. The body of work that has been carried out by scholars represents a variety of shades that enrich the creative argument, and especially when it comes to city-size cultural amenities, or developmental agendas, policy-driven analyses and reports tend to be in this line. Further issues unfold around the deeper social texture of cities, the dynamics that create inequalities, and the understanding of what constitutes creativity. The aim of this paper is to bring to light all these points of discussion, therefore it aims to provide a broader overview structured around three main fields of debate that surround the core problematic of creative class analysis. The former are framed as: 1) contextuality: the problem of cities from all perspectives of time, history, development path, and geography; 2) the human capital vs, creative class debate and its role in regional (urban) development; and 3) creative policies that view cities as sites for cultural production and consumption, and their connection to regional and urban development. 


\section{THE FRAMEWORK: THE CREATIVE CLASS IN RELATION TO REGIONAL PERFORMANCE AND URBAN GROWTH}

The link between creativity, human capital, and economic growth has been already investigated by regional and urban development scholarship, and the role of amenities has gained importance in regional development studies (Clark 2004, Glaeser 1994). Florida examined high-tech boosted cities and observed that the "creative milieu" of cities was inspiring the innovation of companies. This observation has been explored by scholars who have suggested causality in this direction (Lee - Rodríguez-Pose 2014, Lee et al. 2004, Stam et al. 2008). Interestingly, this strand of thought does not question such causality, although entrepreneurship and individuals are different sets of units. However, Florida (2002) suggested that the creative milieu would pull in creatives due to the added value of competing cities, while labor would make its choice based on the accessibility of amenities. Thus, increasing the creative milieu of cultural and creative amenities should be targeted by city governors to pull in knowledgeable individuals such as creatives to generate growth. The 3Ts (tolerance, technology, and talent) are said to be the key attributes for development, and the key indicators of future success; with this claim the thesis is not so different from what regional development scholars have argued for. The 3Ts are interconnected and only together have a synergetic effect on growth:

"Each is a necessary but by itself insufficient condition: To attract creative people, generate innovation and stimulate economic growth, a place must have all three." (Florida 2002: 249)

To attract the creative class - those individuals who are connected through creativity - thus people who...

"do creative work for a living... scientists, engineers, artists, musicians, designers and knowledge-based professionals" (Florida 2002a: XIII)

Cities must show diversity (measured by the gay index of coupled gay people; Florida 2002b), tolerance, and "bohemians" to entertain and maintain the milieu. High-tech firms (Florida 2002b) will locate themselves in regions where coolness (vibrant music scenes, nightlife, galleries), talent (highly educated people), and diversity (gay couples) and amenities exist. Diversity implies low barriers to entry for human capital, thus acceptance of incomers and lifestyles 
in a fluid urban culture of "plug and play" communities (Florida 2005) and the local entrepreneurial field. Informal workplaces and horizontal management structures encourage autonomy and a flow of ideas (Florida 2005), as is known from a body of scholarship (Saxenian 1994, Castells 2000).

The creative class consists of the: 1) super creative core, "whose economic function is to create new ideas, new technology and/or new creative content" (2002a, 8): computer and mathematical occupations; architecture and engineering occupations; life, physical, and social science occupations; education, training, and library occupations; and arts, design, entertainment, sports, and media occupations; 2) creative professionals: management occupations; business and financial operations occupations; legal occupations; healthcare practitioners and technical occupations; and high-end sales and sales management; 3) artistically creative people, who are defined as: authors, designers, musicians, composers, actors, directors, painters, sculptors, artist printmakers, photographers, dancers, artists, and performers. Further classes include the working class of physical laborers and the service class.

Innovation and creativity have been linked by scholars who have investigated the innovation capacity of firms by region in relation to creative cities or the creative economy, proving causality (Lee et al 2004). Lee and Rodrígez-Pose (2014) found that in British cities it is rather middle-sized cities that produce more innovation; a situation that stems not just from creative-related activity. An analysis of Donegan et al. (2008) finds that human capital indices resonate with the talent index, and the 3Ts to be poor predictors of metropolitan jobs and income growth.

\section{REVISITING THE FRAMEWORK: CONTEXTUALITY}

The overall problem of the contextuality that is missing from the creative class framework (Pratt 2008) has raised arguments. Florida's tolerance index is based on the assumption that a large proportion of immigrants and gays directly implies that local society is tolerant of self-expression and a variety of sets of identities, thus creates a favorable climate for idea-generation and business development. This view has been criticized for being static: first, for neglecting the role of the past and how this impacts the present economic system (Storper - Scott 2009), and second, as there is less focus on the dynamic view of change: as an example, the ranking of cities shows that cities with more creative class workers appear to be more livable at one point in time, while no change over time is examined (Donegan et al. 2008). 
A substantial part of the criticism addresses the problem of the claim of diversity and tolerance as assets for capital attraction (thus creative individuals). The tolerance index thesis overlooks the body of scholarship on diversity and how this actually works in urban society contexts. Being tolerant about sexuality does not imply tolerance for religion, race, class or other social attributes and structural divisions. Putnam (2007) suggests that ethnic diversity does not necessarily indicate tolerance, especially in the short term. Looking at neighborhoods with scattered and high ethnic diversity mostly related to new immigration, Putnam measured lower trust and social capital and sees the potential of diversity as an asset for development in the longer term in societies that overcome fragmentation. But Florida's acclaim for diversity and tolerance does not take into account the representation of a vast and rooted part of the population of American society, as it disregards the absence of representation of the AfricanAmerican population in creative cities in the model of the creative class, as pointed out by Markusen, and acknowledged by Florida (Markusen 2006: 1923). Moreover, diverse cities show geographical and social segregation patterns in practice. The submetropolitan perspective (Markusen 2006) is missing from the analysis (Florida 2002a, 2002b, 2005), thus the exact location of high-tech centers (that tend to agglomerate their workers), artists, and the various layers and groups of creatives needs to be addressed. Socioeconomic discrimination concerning the finer geography of city regions is hidden behind regional-scale indicators, argue Storper and Scott (2009). Furthermore, the tolerance index is challenged by migration patterns. In Europe, immigration developed in several waves connected to post-colonial policies or refugee crises. Newer waves of immigration are challenging inclusion, integration, and labor market policies. Crossa and Moore (2009) describe the case of Dublin in a creative-city-policyframing report, where racist assaults against ethnic communities are on the rise. Stockholm is listed as a global hotspot of openness and tolerance that competes for talent by Florida (referenced by Borén - Young 2013a, Florida 2007), but actually immigrants live concentrated together in suburbs outside the cultural infrastructure, socio-culturally isolated, thus disconnected from the creative production of the city (Borén - Young 2013b). Despite the assertion that the creative class is drawn to places that are diverse and tolerant, Bereitschaft (2017) found in central Omahama Nebraska that diversity was not among the most influential factors in the choice of neighborhood, although this parameter was more influential for the latter individuals than among the non-creative group. Contextuality also implies historical patterns of inward migration to cities listed as metropolises of creativity. Clifton, Hooke and Hansen (2013) incorporate the spatial dimension into the economic-historical-institutional one by examining the creative class and locations through the lens of the varieties of capitalism it 
is being nested into by comparing a liberal (UK) and a coordinated (Sweden) market economy (based on Soskice 1999).

\section{THE CREATIVE CLASS AND HUMAN CAPITAL IN REGIONAL AND URBAN DEVELOPMENT}

Which notion is most suitable for predicting economic growth in regional or urban development was tested on a series of data and contexts. The importance of human capital in explaining productivity and growth across regions was emphasized by the strand of "new economic geography" (Krugman 1991), and the economic theories of endogenous growth (Romer 1990). Adding a focus on knowledge (all the scholarship that has evolved around the knowledge economy and its role in economic prosperity) and creatives intuitively proved to be a valuable insight. However, scholars have drawn attention to the weakness of the construct in empirical testing. Despite the stress on the element of creativity, as argued by Florida, forthcoming research has mainly operationalized the creative class thesis based on national statistics about occupations based on the classification system provided by Florida (2002).

First of all, a focal argument behind the denial of the notion of the creative class is exactly the argument that creativity is not tied to occupational roles (Markusen 2006). As a consequence, this strand of scholarship on urban policies that has evolved around creativity as a source neglects the disciplinary theories and research on creativity itself. Scholarship aimed at deeply understanding and complementing this deficiency concentrates on the super-creative core of artists and bohemians and their role in urban development and attracting talent (Scott 2004, Markusen 2006, Alfken et al. 2013, Borén - Young 2013a, Van Heerden Bontje 2016, Triuneh et al. 2017). Second, the creative class is viewed as a new category for understanding how highly educated labor predicts regional growth; this strand of research is testing and fine-tuning the types of human capital vs. creative class framework.

The human capital approach to understanding the factors of growth is connected to understanding knowledge as a source, as well as investigating how human capital is geographically spread across regions and contributes to development. Scholarship in urban development has suggested that amenities do play a role in the choices of high human capital labor (Storper -Scott 2009). Glaeser, one of the proponents of the role of the educated and highly skilled in making the urban economy, was also a proponent of the role of natural and built amenities in cities and regions. Reflecting on the creative class thesis, Glaser (2005) examines the problem of human capital vs. creative class. First of all, he 
claims that the two notions have no difference from an economic perspective. Then, testing the bohemian index, Glaeser found no empirical evidence for building policies and urban development programs around it; however, he does not deny that human capital and a favorable environment of amenities is correlated to growth and is of more significance in times of high human capital than earlier (e.g. under industrial capitalism).

Addressing the human capital agenda, the gay index was found to be strongly correlated with educational attainment (Glaeser 2005), with impacts severely reduced and similar to those of lesbians and unmarried couples (Clark 2004), implying on one hand that diversity is seen through a narrow lens, and on the other that the relationship between tolerance, class, and technology is less clear. After examining the attractiveness-people-jobs causality problem Østbye et al. (Østbye et al. 2018) suggested that human capital is rather an attribute of people than jobs, while the notion of a creative class is more applicable to jobs, not people, despite the fact that scholarship tends to think of it the other way around.

Furthermore, the notion of the creative class has been unpacked by many scholars and found to be weak in relation to classifications of class identity (Peck 2005, Markusen 2006, Scott 2006, McGranahan - Wojan 2007). The notion of "class" itself may be criticized for not being a valid sociological term. It does not refer to a combination of shared interests, or unifying traits, or shared structural features that lead to a set of actions. Florida's creative class has been viewed as a set of occupations grouped on the basis of educational attainment, with no explicit relationship to creativity, in which individuals - for example, artists - do not share a common cause with other members such as scientists, engineers, managers, or lawyers (Markusen 2006). In his measurements (2002a, 2002b), Florida uses the occupational codes for high educational attainment; an approach that is grounded in the theoretical concept of human capital used by economists and regional economists. Peck (2005) finds that the definition is broad and includes semiroutine financial and personal services, although one-third of the US workforce is estimated to be engaged in creative economic activity (Florida 2002a).

Human capital is most often measured through educational attainment. As a contra-argument, Marlet and Van Woerkom (2007) have measured the growth of employment in Dutch cites and found that both frames predict employment growth, but the creative approach performed better at explaining employment growth in the financial, commercial services, and startup sector, implying a refined view of the creative frame based on occupations. Further refinements were developed for testing under what conditions the concept of the creative class has more powerful predictive force in terms of geographical distribution compared to different types of human capital associated with openness and tolerance (Mellander - Florida 2006, Florida et al. 2008, etc.). 
One strand of scholarship about urban policies has evolved around creativity as a source, but neglects disciplinary theories and research on creativity itself. More specifically, Pratt points out (2006) that the listing of key creative occupations, including the arts sector, was already done in the early 1990s in the UK. He warns of the problem of isolating individuals and occupations from context and from other industries, businesses, and society. One further focal argument for the denial of the notion of a creative class is the argument that creativity is not tied to occupational roles (Markusen 2006).

\section{The Problem of Causality: City, Talent, Growth}

Policies have been adapted based on the primary claim that creative talent will be attracted by cities and regions. It is assumed that for such an attraction-based effect, firms will emerge in this entrepreneurial milieu. In what follows, studies that tested this argument to make comparisons or develop unique suggestions are cited.

Looking at the luring effect of the creative milieu, Clark (2004) found that top staff in highly dynamic firms are less aware of the cultural amenities that they could indulge in due to their workloads. However, a creative milieu allows for the possibility of adapting the work amenities of firms to attract mid- and lowerlevel staff, but causality in this case runs in the reverse direction.

Empirical data gathered in relation to studying local and regional employment growth in Canada showed that human capital flowed to cities whose economic performance had increased, not the other way around (Shearmur 2007). In contrast, an overarching study of Boschma and Fritsch (2009) found a positive relationship between the creative class and employment growth, tolerance, and openness as factors stimulating creatives to relocate to highly urbanized regions. Storper and Scott argue that urban growth is directly related to the economic geography of production and must be related to the location of firms and movements of labor that are in recursive interaction (2009: 147). The related comprehensive analysis acknowledges the importance of amenities, but holds to the claim that the main driving forces for attracting labor are wages and work. Thus, findings suggest that it is primarily jobs and production that create prosperity. Based on data from Finland, Norway, and Sweden in the 2000s, Østbye, Moilanen, Tervo, and Westerlund (2018) found that through "circular causation" creative-class jobs follow other jobs and vice versa, thereby breaking with the unidirectional understanding of the causation issue that has led to such a lively debate among scholars. Interestingly, Hansen, Asheim and Vang (2009), from examining eight European countries, found that knowledge-intensive firm 
start-ups were negatively correlated with the "creative class," which finding brings us closer to the problematic of the contextuality argument.

\section{Labor Market and Mobility Assumptions about the Creative Class}

One strand of research has focused on the claim that amenities, openness, tolerance, and production systems are the main pulling factors for creatives and shape labor markets. On the one hand, the European labor market shows differences to that of the US in terms of its complexity and variety on a regional level, also framed by the differences in the historical patterns of the different countries. Asheim (2009) and Hansen and Niedomysl (2009) pointed out the fact that the coordinated markets of the Nordic countries in Europe provide a contrast with their lower levels of interurban competition and smaller urban centers and welfare systems that are less liable to foster job mobility, hence the US market economy is more likely to induce mobility and dynamism. Musterd and Gritsay (2012) suggest that diversity and a long urban history play a role in any differences.

A further problem related to the notion of the creative class is the assumption of mobility of creative labor: this has been challenged in several ways. The issue of causality is further explored in the theme of migration dynamics (how and why do creatives move in space), and if this supports the argument of attractivity (i.e. do creatives move to attractive places, and do jobs and growth follow?). As empirical dataset analyses did not support the assumption of causality in many cases in a straightforward way, sociological investigations have looked at the problem closely. One perspective involves trying to understand the preferences of the creative class in relation to how they choose their locations in line with arguments about the attraction of amenities. Storper and Scott (2009) argued that an absence of economic opportunities would deter people from taking up desired occupations, no matter how much a city's attractiveness is improved. The former found that artists eventually settle when they find a location in which multiple factors are connected: labor demand, economic specialization, and so forth.

Further research in the United States (Markusen - Schrock 2006, Scott 2010, Bereitschaft 2017) revealed that employment opportunities and wages were the primary drivers, while amenities had a weaker impact or none. Scott (2010) noted that finding work was of more significance, especially to those with high human capital, than the presence of amenities. The same was found in Scotland (Houston et al. 2008) in the context of post-industrial societies, and in Tasmania (Verdich 2010) where outdoor amenities, a sense of community and downshifting were 
the primary factors in attracting creatives to Launceston, only then followed by an appreciation of cultural amenities. In the setting of a small city-region amenities were not emphasized by in-migrant creatives; this finding may be connected to the problem of the centrality of Canadian cities compared to those of the US (Lepawsky et al. 2010). The same was found in Ireland (Boyle 2006) in the context of the Celtic Tiger, a developmental state, despite the amenities and the "soft" factors that play a role among the communities of creative expats in Dublin, thus the technology-talent-tolerance explanation should be revised. In the bohemian Prenzlauer Berg of Berlin, non-creatives demonstrated more attraction to locational preferences in their residential choices than creatives than was a priori assumed (Van Herden - Bontje 2016). Chow (2017) adds a further perspective conerning how and why creatives decide on their location between cities and finds that socio-political context can play an overwhelming role. In connection with the migratory forces related to the "Rise of China" and the handover of Hong Kong, the migratory moves of Hong Kong creatives toward mainland Benjing or Shanghai, besides intersectional factors such as gender, age and life-cycle, tell us about the geopolitical lens that should be considered (Chow 2017).

Studies have also focused on sub-segments of the creative class, thereby following and stretching the classification of the Florida (2002) framework, as sets of actors show diverse patterns. This reveals again the problem of the notion of the creative class in relation to the diversity of actors and occupations, allowing a more profound investigation of preferences and the mechanisms behind mobility. A further set of questions stem from the assumption that creatives demonstrate more flexible and independent behavior than non-creatives, and show a preference towards mobility. However, creatives were found to be only marginally more mobile than non-creatives (as defined by occupation) in a study that examined the Swedish and Nordic-European context (Hansen - Niedomysl 2009).

Despite the fact that arguments about the creative class were developed to help understand the metropolitan and regional dimensions of development, research has widened its focus to rural areas and small-scale cities, as well as networks of cities. Interestingly, although the latter two areas accord with the argument about the variety of city development patterns, studies have not attempted to cover larger periods of time to understand creative class dynamics. Most of the related papers are insightful in terms of their analysis of a given set of dynamics more narrowly defined in time and space. The Danish pattern is applicable for describing the small-town context of the creative class, and helped identify the different factors that attract business. In this scenario, the local government invests in cultural amenities, allowing for the traditional pattern of small- 
towns being perceived as the "hinterland" (Sørensen et al. 2010). Amsterdam is the largest city with flourishing creative industries in a network of smaller cities and settlements in the Netherlands. Stam, Jeroen, De Jong, and Marlet (2008) have found that employment growth and the presence of the creative class are correlated in all cities. Still, when it comes to culture, the latter draw on centrality as explained by the fact that the creative industries themselves and cultural production are overwhelmingly located in Amsterdam. A similar finding is reported by Musterd and Gritsay (2012) who studied respondents from thirteen European countries.

Shifting the focus to the rural dimension, the non-metropolitan areas of the US showed a similar pattern to the large cities. This again underlines the differences in urbanization patterns of the different continents, countries, and settings. McGranahan and Wojan (2007) found $20 \%$ of the employment in creative class jobs to be located in non-metropolitan environments compared to the $31 \%$ in large cities, with similarities in occupational structure and the former often associated with universities. Outdoor amenities were found to be important as factors in the choice of location for creatives, but not the leading drivers. In an interesting leap from the original set of measures designed for large cities, the creativity agenda has been extended to the rural context for tourism-driven development. Refining the policy-makers' toolkit to rural dimensions Thulemark and Hauge (2014) examined how the wide framework of the creative class fit this context. By investigating a tourist ski-resort, adding overarching territorial assets as the fourth $\mathrm{T}$, and reconstructing the 4Ts, the findings of the former ended up incorporated into a novel scheme that lies outside the actual framework and debate about the original theses of creative class. These theoretical leaps highlight the directions that the original framework has inspired and reinforce its underlying argument about performative leisure activity as a proxy for the presence of the privileged in given geographical areas.

Further studies have questioned the urban hierarchy of cities in the locationrelated decisions of the creative class. European urban systems tend to have stronger hierarchies: for example, in Eastern Europe or in Sweden (Hansen Niedomysl 2009, Borén - Young 2013a). Urban patterns vary across Germany, the Netherlands, England, and Wales, bringing into question the different results related to the distribution of the creative class obtained by Bochma and Fritsch (2009). Dominant urban regions may have been historical centers for growthrelated elements, thus pulling in talent, technology, and diversity propelled by inmigration, as well as having institutionalized cultural amenities. A comparative study of 444 city-regions in eight European countries revealed that the creative class is less attracted to smaller settlements than the overall population, a finding related to the fact that the market threshold for creative jobs and services is lower 
(Lorenzen - Andersen 2009). The centrality problem may be behind findings from St. Johns Canada (Lepawsky et al. 2010) that suggest that the presence of creatives is rather a matter of correlation within urban hierarchies than a result of competition between megapolises, as suggested within the US context by Florida (2002, 2005). Clifton, Cooke, Hansen (2013) call for more insight into how the Varieties-of-Capitalism effect (coordinated vs. liberal markets) works in relation to the regional hierarchy effect: the authors find that the creative class is more evenly distributed in spaces with a higher urban hierarchy in Sweden than in the UK, where the creative core seems to be more sensitive to urban hierarchy.

Although the concept of embeddedness is applicable to understanding economic performance in dense social environments, as we have known since Polányi (1957) and Granovetter (1985) and the vast scholarship behind this about the role of networks, it seems that the creative class framework lacks this link. Florida's framework focuses on the "hard" (e.g. job availability) and "soft" (diversity, openness, tolerance) factors of attracting creatives and boosting economic development. Interestingly, the entire legacy of Granovetter (1973) concerning the role of ties in jobs is disregarded. Some studies that aimed at understanding the mobility of creatives, or how creatives and industries are structured, found evidence in this domain. For example, Musterd and Gritsay (2012) argue that social connections (personal, professional links) are at the fore, and hard and soft conditions play less of a role, according to the respondents of thirteen European cities. Sedita (2008) examined the networks of organizations and jobs to understand the connection between the production of the arts and regional performance in Veneto. Another argument comes from Berlin - a city that adopted the creative agenda early on - where creativity tends to be clustered in geographical space that fosters inter-personal interaction which may play a larger role in the former than in other industries (Staber 2008).

\section{CULTURAL PRODUCTION, CONSUMPTION, AND URBAN AND REGIONAL DEVELOPMENT}

There are at least three approaches to the creative and cultural industries and locating them in cities for regional growth. One focuses on the production side of culture as a lure that increases city attractiveness (Bianchini - Landry 1995, Landry 2000); another is concerned with consumption patterns (Zukin 1982, 1995, Scott 2004) that should be considered more complex than presently suggested, while the third strand argues for the interwovenness of production and consumption in cultural practices (Pratt 2004, 2005, 2008). 
Urban-development-related discussions have been centered on the concept of the so-called creative city (Landry 2000), an idea that was swiftly inspired by arguments about the creative class and talent attraction (Florida 2002a, $2005)$ that embrace the city attractiveness discourse. Cities adapted Landry's and Florida's ideas and converted them into policies of problem-solving, in line with a shift from managerial to entrepreneurial forms of governance (Harvey 2002, Jessop - Sum 2000), involving shifting the focus from providing services towards raising capital to fostering local economic development and employment growth. Specifically, the UK has seen many cases of creative and cultural city development agendas with soft policy measures for attracting investment, and large, publicly funded cultural infrastructure to increase attractiveness to talent and capital, with no regard to measure and centrality (Chapain - Comunian 2009). Studies inform us about the spatial mapping of creative industries (Staber 2008, Lange et al. 2008), mirroring the division of labor in inter-city competition. For example, by listing London as the core for advertising, design, fashion, video, photography and publishing and the media industries, and Birmingham and Newcastle-Gateshead for architecture, arts, antiques, computer games, and electronic publishing (Chapain - Comunian 2009) - or viewing Dublin as a "lifestyle destination" (Crossa - Moore 2009), and seeing Germany Berlin, Hamburg, Munich, Cologne as hubs for collecting a variety of artists (Alfken et al. 2013) or London as agglomerating designers (Reimer et al. 2008).

The consumption side of stressing the need for a cultural and creative face to a city is concerned with urban branding, thus building upon a strategy that communicates to consumers (residents, tourists, investors) and making this suitable for conveying meanings and narrating identities based on the cultural heritage, subcultures, cool environments, and so forth (Bookman 2014). The strand of theory that stresses the complexity of the relationship of production and consumption emphasizes that neither perspective should be the driving force behind policy (Peck 2005, Pratt 2008). Culture in cities is a hybrid practice that integrates the perspectives of production and consumption (Pratt 2011), as cities are sites of both (Hall 2000), where cultural industries link manufacturing and services (Pratt, 2008: 108). The critical scholarship about the creative city argues for less normative prescriptions that draw on contextuality and situativeness (Pratt 2008, Potts et al. 2008), indicating that creativity is a process situated in socio-economic structures. Cultural theorists see creativity as a source of value creation that results in cultural and economic innovation, while in static models it is viewed as part of the environment or contextual milieu (Potts et al. 2008).

The main criticism is that instrumental creative city policies target boosting consumption and the use and deployment of creativity which should be 
enhanced using non-instrumental policies (Pratt 2008). In this vein, Boren and Young (2013) point to the "creative policy gap" inasmuch as the practices of policymakers and those engaged in creative activities should be more inclusive. The problems of gentrification and large-scale investment projects in culture were discussed prior to the creative city movement, fueled by the talent-attraction paradigm, as problems of neoliberal governance and the commodification of urban space in culture capitals (Zukin 1982, 1995). The latter process involves large investments aimed at developing "creative spaces," implying strategic interests that spur displacement and generate social and political costs (Catungal et al. 2009). Finally, the creative quarters that lure visitors and create relatively high levels of agglomeration my reduce the amount of affordable space for the creatives themselves (galleries, housing, etc), as artists tend to be highly sensitive to these factors (Peck 2005). These processes have been extensively documented by researchers (Alfken et al. 2013). Bookman (2014) provides an illustrative example of how intensified redevelopment was followed by artist-led revitalization but ended in a situation where...

"greasy spoon diners and used bookstores are giving way to high-end boutiques and hair salons, and some independent artists and arts groups have been displaced with higher rents..."

The branding strategies of cities also imply converting public spaces into "consumption hubs" with boutique consumption spaces that are unsustainable (Pratt 2011). As an outlook, more recent scholarship is concerned with the postcrisis structural problems of unemployment, youth, and segregation in cities. McRobbie's (2016) work, particularly, takes stock of how the notion of creativity holds in large European culture capitals such as London, Berlin, and Milan, with a vision of what the structure of work and creative entrepreneurship look like in a contemporary context after the "rosiness" of Floridian creative city policies, and suggests what the future of the "new creative economy" will be.

\section{CONCLUSIONS}

Since Richard Florida's $(2002,2004,2005)$ arguments about the role of the creative class in the urban regeneration of cities in the North-American context, much debate has occurred. Sets of criticisms address the contextual differences of development paths based on space, history, and urban development patterns; the causality problem, and the set of attributes that should be used in the 
measurement of the former. The strand of scholarship concerning if and how human capital and creative class frameworks differ in their interpretation of urban local development emerged quite early on. Florida's suggestion was still a clear and fresh enough approach to reach out to a set of cities that implemented policies to increase their attractiveness to the creative class, converting spaces into cultural infrastructure in the hope of luring talent that would invigorate the economy. As soon as these policies spread across cities, criticism about the dynamics and the understanding of creativity was raised.

Today, in the post-crisis era, cities are facing gentrification-, segregation-, and unemployment-related issues, in which a new era of the creative economy is being born. In a recent book, Florida (2017) himself has redesigned his recommendations. The notions of the creative class and creative industries in the domain of regional development and urban policies have gone through a reinterpretation in past decades, with further shades of interpretation, arguments, and enrichment with empirical evidence from a variety of contexts. This paper has provided a synthesized overview of the main strands without giving a full list and account of the whole body of work that has been created. The cited and non-cited studies related to this overview point in the direction of the possibility of making comparisons using a defined set of indices that capture the notion of the creative class in different cities. It turns out that the socio-economic, ethnographic, and historical-political context are re-defining the initially unified view of the contemporary path of development of cities and regions. From this angle, arguments about the creative class and the creative economy should be fundamentally revisited.

\section{REFERENCES}

Alfken Ch. - Broekel T. - Sternberg R. (2013), "Factors Explaining the Spatial Agglomeration of the Creative Class: Empirical Evidence for German Artists", European Planning Studies https://doi.org/10.1080/09654313.2014.9 79767 (Accessed: 20 May 2018).

Asheim, B. - Hansen, H. K. (2009), "Knowledge Bases, Talents, and Contexts: On the Usefulness of the Creative Class Approach in Sweden", Economic Geography, Vol. 85, No 4, pp. 425-442 https://doi.org/10.1111/j.19448287.2009.01051.x.

Bereitschaft B. (2017), "Do "creative" and "non-creative" workers exhibit similar preferences for urban amenities? An exploratory case study of Omaha, Nebraska", Journal of Urbanism: International Research on Placemaking 
and Urban Sustainability, Vol. 10, No 2, pp. 198-216, https://doi.org/10.1080/ 17549175.2016.1223740.

Bookman, S. (2014), "Urban Brands, Culture and Social Division: Creativity, Tension and Differentiation Among Middle Class Consumers", Journal of Consumer Culture, Vol. 14, No 3, pp. 324-342.

Borén T. - Young C. (2013a), "The Migration Dynamics of the "Creative Class": Evidence from a Study of Artists in Stockholm, Sweden", Annals of the Association of American Geographers, Vol. 103, No 1, pp. 195-210, https:// doi.org/10.1080/00045608.2011.628263.

Boren, T. - C. Young (2013b), "Getting Creative with the 'Creative City' Towards New Perspectives on Creativity in Urban Policy", International Journal of Urban and Regional Research, Vol. 37, No 5, pp. 1799-1815.

Boschma A. and Fritsch M. (2009), "Creative Class and Regional Growth: Empirical Evidence from Seven European Countries", Economic Geography, Vol. 85, No 4, pp. 391-423. https://doi.org/10.1111/j.19448287.2009.01048.x.

Boyle, M. (2006), "Culture in the Rise of Tiger Economies: Scottish Expatriates in Dublin and the 'Creative Class' Thesis", International Journal of Urban and Regional Research, Vol. 30, No 2, pp. 403-426. https://oi.org/10.1111/ j.1468-2427.2006.00661.x.

Castells M. (2000), The rise of the Network Society. The Information Age: Economy, Society and Culture, Blackwell Publishers Inc. Cambridge, US.

Catungal, J.P. - Leslie, D. - Hii, Y. (2009), "Geography of Displacement in the Creative City. The Case of Liberty Village Toronto", Urban Studies, Vol. 46, No 5-6, pp. 1095-1114.

Chapain C. - Comunian R. (2009), "Creative Cities in England. Researching Realities and Images", Built Environment, Vol. 35, No 2, pp. 220-237.

Chow Y. F. (2017), "Exploring creative class mobility: Hong Kong creative workers in Shanghai and Beijing", Eurasian Geography and Economics, Vol. 58, No 4, pp. 361-385, https://doi.org/10.1080/15387216.2017.1365311.

Clark T. N. (2004), "Gays and Urban Development. How are they linked", in: Clark T. N. The City as an Entertainment Machine, Research in Urban Policy. Emerald Group Publishing Limited, pp. 221-234.

Clifton, N. - Cooke, P. - Hansen, H. K. (2013), "Towards a Reconciliation of the 'Context-less' with the 'Space-less'? The Creative Class across Varieties of Capitalism: New Evidence from Sweden and the UK", Regional Studies, Vol. 47, No 2, pp. 201-215,

Crossa V. - Moore N. (2009), "Innovating to Compete. Dublin as a Smart and Creative City", Building Material, Vol. 18, pp. 84-89. https://doi.org/10.1080/ 00343404.2012.665991. 
Donegan, M. - Drucker, J. - Goldstein, H. - Lowe, N. - Malizia, E. (2008), "Which Indicators Explain Metropolitan Economic Performance Best? Traditional or Creative Class", Journal of the American Planning Association, Vol. 74, No 2, pp. 180-195, https://doi. org/10.1080/01944360801944948.

Eriksson, R. H. - Hansen H. K. - Winther L. (2017), "Employment growth and regional development: industrial change and contextual differences between Denmark and Sweden", European Planning Studies, Vol. 25, No 10, pp. 17561778, https://doi.org/10.1080/09654313.2017.1338673.

Florida, R. L. (2002a), The Rise of the Creative Class: and How It's Transforming Work, Leisure, Community and Everyday Life, New York, Basic Books

Florida, R. L. (2002b), "The economic geography of talent", Annals of the Association of American geographers, Vol. 92, No 4, pp. 743-755.

Florida, R. L. (2004), Cities and the Creative Class, London, Routledge

Florida, R.L. (2005), The Flight of the Creative Class: The New Global Competition for Talent, New York, Collins

Florida, R. L. (2017): The New Urban Crisis: How Our Cities Are Increasing Inequality, Deepening Segregation and Failing the Middle Class and What We Can Do About It, Basic Books

Florida, R. L. - Mellander Ch. - Stollarick K. (2008), "Inside the Black Box of Regional Development, Human Capital, The Creative Class, and Tolerance", Journal of Economic Geography, Vol. 8, pp. 615-649.

Glaeser, E. L. (2005), "Review of Richard Florida's The Rise of the Creative Class", Regional Science and Urban Economics, Vol. 35, pp. 593-596. https:// doi.org/10.1016/j.regsciurbeco.2005.01.005.

Glaeser, E. L. - Redlick Ch. (2008), "Social Capital and Urban Growth", NBER Working Paper Series, WP14374, Cambridge MA, http://www.nber.org/ papers/w14374 (Accessed: 20 May 2018).

Granovetter, M. S. (1973), "The Strength of Weak Ties", American Journal of Sociology, Vol. 5, No 1, pp. 1360-1380.

Granovetter, M. S. (1985), "Economic Action and Social Structure. The Problem of Embeddedness", American Journal of Sociology, Vol. 91, No 3, pp. 481-510. Hall, P. (2000), "Creative cities and economic development", Urban Studies, Vol. 37, No 4, pp. 639-649.

Houston, D. - Findlay, A. - Harrison, R. - Mason, C. (2008), "Will attracting the "creative class" boost economic growth in old industrial regions? A case study of Scotland", Geografiska Annaler: Series B, Human Geography, Vol. 90, No 2, pp. 133-149.

Jacobs, J. (1961), The Death and Life of Great American Cities, New York, Random House 
Jessop B. - Sum, Ngai-Ling (2000), "An Entrepreneurial City in Action: Hong Kong's Emerging Strategies in and for (Inter)Urban Competition", Urban Studies Journal Limited, Vol. 37, No 12, pp. 2287-2313.

Landry, C. - Bianchini F. (1995), The Creative City, Demos. https://www.demos. co.uk/files/thecreativecity.pdf (Accessed: 20 May 2018).

Landry, C. (2000), The Creative City: A Toolkit for Urban Innovators, London, Earthscan

Lange B. - Kalandides A. - Stöber B. - Mieg H.A. (2008), "Berlin's Creative Industries. Governing Creativity?", Industry and Innovation, Vol. 15, No 5, pp. 531-548.

Lee, S. - Florida, R. L. - Ács, Z. J. (2004), "Creativity and entrepreneurship: a regional analysis of new firm formation", Regional Studies, Vol. 38, No 8, pp. 879-891.

Lepawsky J. - Phan Ch. - Greenwood R. (2010), "Metropolis on the margins: talent attraction and retention to the St. John's city-region", The Canadian Geographer, Vol. 54, No 3, pp. 324-346.

Krugman P. (1991), "Increasing Returns and Economic Geography”, Journal of Political Economy, Vol. 99, No 3, pp. 483-99.

Marlets, G. - Van Woerkom, C. (2007), "The Dutch Creative Class and How It Fosters Urban Employment Growth”, Urban Studies, Vol. 4, No 1, pp. 26052626.

McGranahan, D. A. - Wojan, T. R. (2007), "Recasting the creative class to examine growth processes in rural and urban counties", Regional Studies, Vol. 41, pp. 197-216.

McGranahan, D. A. - Wojan, T. R. - Lambert, D. M. (2011), "The rural growth trifecta: outdoor amenities, creative class and entrepreneurial context", Publications from USDA-ARS /UNL Faculty. 714. http://digitalcommons.unl. edu/usdaarsfacpub/714.

McRobbie, A. (2016), Be Creative: Making a Living in the New Culture Industries, Cambridge, UK, Polity Press

Mellander Ch. - Florida, R. L. (2006), The Creative Class or Human Capital? Explaining Regional Development in Sweden. https://www.creativeclass.com/ rfcgdb/articles/The_Creative_Class_or_Human_Capital.pdf

Musterd, S. - Gritsai, O. (2012), "The Creative Knowledge City in Europe. Structural Conditions and Urban Policy Strategies for Competitive Cities", European Urban and Regional Studies, Vol. 20, No 3, pp. 343359.

Østbye, S. - Moilanen, M. - Tervo, H. - Westerlund, O. (2018), "The creative class: do jobs follow people or do people follow jobs?", Regional Studies, Vol. 52, No 6, pp. 745-755, https://doi.org/1080/00343404.2016.1254765 
Peck J. (2005), "Struggling with the Creative Class", International Journal of Urban and Regional Research, Vol. 29, No 4, https://doi.org/10.1111/j.14682427.2005.00620.x (Accessed: 15 May 2018).

Peck J. (2012): "Recreative City: Amsterdam, Vehicular Ideas and the Adaptive Spaces of Creativity Policy", International Journal of Urban and Regional Research, Vol. 36, No 3, pp. 462-485, https://doi.org/10.1111/j.14682427.2011.01071.x

Polányi, K. (1957), “The Economy as an Instituted Process", in: Karl Polanyi - Conrad M. Arensberg - Harry W. Pearson (eds.), Trade and Market in the Early Empires. New York, Free Press, pp. 243-270.

Pratt, A. C. (2005), "Cultural industries and public policy: an oxymoron?", International Journal of Cultural Policy, Vol. 11, No 1, pp. 31-44.

Pratt, A. C. (2008), "Creative cities: the cultural industries and the creative class", Geografiska Annaler: Series B, Human Geography, Vol. 90, No 2, pp. 107-117.

Pratt, A. C. (2011), "The Cultural Contradictions of the Creative City", City Culture and Society, Vol. 2, No 3, pp. 123-130.

Potts, J. - Hartley, J. - Banks, J. - Burgess, J. - Cobcroft, R. - Cunningham, St. - Montgomery, L. (2008), "Consumer Co-creation and Situated Creativity", Industry and Innovation, Vol. 15, No 5, pp. 459-474.

Putnam, R. D. (2007), "Diversity and Community in the 21st Century: The 2006 Johan Skytte Prize Lecture", Scandinavian Political Studies [Internet]. Vol. 30, pp. 137-174. https://doi.org/10.1111/j.1467-9477.2007.00176.x.

Reimer, S. - Pinch, S. - Sunley, P. (2008), "Design spaces: agglomeration and creativity in British design agencies", Geografiska Annaler: Series B, Human Geography, Vol. 90, No 2, pp. 151-172.

Romer P. (1990), "Endogenous Technological Change", Journal of Political Economy, Vol. 98, No 5, pp. S71-102 (Accessed: 20 May 2018).

Saxenien A. L. (1994), Regional Advantage. Culture and Competition in Silicon Valley and Route 128, Harvard University Press

Scott A. J. (2004), "Cultural-Products Industries and Urban Economic Development. Prospects for Growth and Market Contestation in Global Context", Urban Affairs Review, Vol. 39, No 4, pp. 461-490, https://doi. org/10.1177/107808740326125.

Sedita, S. (2008), "Interpersonal and Inter-Organizational Networks in the Performing Arts. The Case of Project-Based Organizations in the Live Music Industry", Industry and Innovation, Vol. 15, No 5, pp. 493-511.

Sørensen, F. - Fuglsang L. - Sundbo, J. (2010), "Experience economy, creative class and business development in small Danish towns", Urban Research \& Practice, Vol. 3, No 2, pp. 177-202, https://doi.org/10.1080/17535069.2010.481376. 
Stam, E. - Jeroen, P.J. - De Jong, J. P. J. - Marlet, G. (2008), “Creative industries in the Netherlands: structure, development, innovative- ness and effects on urban growth", Geografiska Annaler: Series B, Human Geography, Vol. 90, No 2, pp. 119-132.

Storper, M. - Scott, A. J. (2009), "Rethinking human capital, creativity and urban growth", Journal of Economic Geography, Vol. 9, pp. 147-167.

Stuber U. (2008), "Network Evolution in Cultural Industries", Industry and Innovation, Vol. 15, No 5, pp. 569-578.

Thulemark, M. - Hauge, A. (2014), "Creativity in the Recreational Industry: Re-conceptualization of the Creative Class theory in a Tourism-dominated Rural Area", Scandinavian Journal of Public Administration, Vol. 18, No 1, pp. 87-105.

Tiruneh, E.A. - Sacchetti, S. - Tortia, E. (2017), "Do art experts (bohemians) attract high-skilled professionals? Evidence from Panel Data in German Regions", Competition and Change, Vol. 22, No 1, pp. 81-97, https://doi. org/10.1177/1024529417744143.

Van Heerden, S. - Bontje, M. (2016), "What about Culture for the Ordinary Workforce? A Study on the Locational Preferences of the Creative Class in Prenzlauer Berg, Berlin", Journal of Urban Affairs, Vol. 36, No 3, pp. 465481, https://doi.org/10.1111/juaf.12048.

Zukin, S. (1982), Loft Living: Culture and Capital in Urban Change, Baltimore, Johns Hopkins University Press

Zukin, S. (1995), The Cultures of Cities, Cambridge, Blackwell 